\title{
Relação entre uso do solo e comportamento hidrológico na Bacia Hidrográfica do Ribeirão João Leite ${ }^{1}$
}

\author{
$\overline{\text { Eduardo H. M. dos Santos }{ }^{2} \text {; N ori P. G riebeler }{ }^{3} \& \text { Luiz F. C. de Oliveira }{ }^{4}}$
}

\section{RESU MO}

0 comportamento hidrológico de bacias hidrográficas decorre principalmente da variabilidade dos processos climáticos e do uso do solo. A Bacia do Ribeirão João Leite constitui-se no principal manancial de abastecimento de Goiânia e, recentemente, foram verificadas intensas modificações no uso do solo e disponibilidade de água. N este contexto, tevese como objetivo classificar o uso do solo entre 1979 e 2005 e realizar a associação do escoamento com o uso do solo e a variabilidade pluviométrica. Para isto, se utilizaram imagens Landsat dos anos de 1979, 1989, 1997 e 2005, além de dados fluviométricos e pluviométricos disponibilizados pela Agência Nacional de Águas (ANA). 0 uso do solo foi marcado pelo desmatamento de 17,8\% da vegetação nativa, expansão das áreas de urbanização e agricultura em 6,6 e 15,2\%, respectivamente, e pela expressiva área de pastagens. Constatou-se tendência de redução no escoamento explicada, em parte, pela redução do regime de chuvas; contudo, devido ao expressivo aumento da água captada e à ausência de registros históricos, houve dificuldade na associação qualitativa entre o escoamento e o uso do solo, apesar de serem gerados modelos por regressão linear com coeficientes de determinação $\left(R^{2}\right)$ acima de 0,75 .

\section{Relationship between land use and hydrological behavior in the 'Ribeirão João Leite' watershed}

\begin{abstract}
The hydrological behavior of watersheds derives mainly from climate variability and land use. The 'Ribeirão João Leite' watershed is the main sourse of water supply in Goiânia city, and recently intense modifications were observed in the land use and availability of water. In this context, this work proposes to classify the land use between 1979 and 2005 and establish the association of the runoff with the land use and climate variability. For this, Landsat images from the years 1979, 1989, 1997 and 2005 were used as well as flow and rainfall data provided by the Agência Nacional de Água (ANA). The land use was marked by $17.8 \%$ of deforestation, expansion of the urbanization and agriculture corresponded to 6.6 and $15.2 \%$, respectively, and by significant areas of pasture. A trend of reduction in flow was observed that could be explained, in part, by a reduction in the rainfall regime. However, due to the significant increase of water withdrawal and the lack of historical records, there was difficulty in qualitative association between the runoff and the land use in spite of generating linear regression models with coefficients of determination $\left(R^{2}\right)$ above 0.75 .
\end{abstract}

Key words: water resources, flow, Goiânia

\footnotetext{
${ }^{1}$ Parte da Tese de Doutorado do primeiro autor apresentada à UFG, como requisito parcial à obtenção do título de Doutor em Agronomia, área de concentração Solo e Água

2 IFT - Campus U rutaí, Fazenda Palmital Km 2,5, zona rural, CEP 75790-000 ,U rutaí, GO. Fone: (64) 3465-1900. E-mail: ehmsantos1@bol.com.br 3 Escola de Agronomia e Engenharia de Alimentos/UFG. Rodovia Nova Veneza, Km 0, CP 131, CEP 74001-970, Goiânia, G0. Fone: (62) $3521-1534$. E-mail: griebeler@yahoo.com.br

4 Departamento de Engenharia/UFLA, CP 3037, CEP 37200-000, Lavras, M G. Fone: (35) 3829-1481 E-mail: Ifco@pq.cnpq.br
} 


\section{INTRODUÇÃO}

A água é um recurso natural que apresenta os mais variados usos e é indispensável ao desenvolvimento humano. A manutenção deste recurso finito em padrões de quantidade e qualidade com o objetivo de atendimento aos seus múltiplos usos, representa um desafio para as sociedades. Desta maneira, uma das maiores demandas ambientais atuais consiste no desenvolvimento de estudos envolvendo o processo de formação do escoamento fornecendo subsídios para a tomada de decisões por parte dos responsáveis pela gestão dos recursos hídricos.

O regime hidrológico de um rio é afetado pelo uso do solo, variabilidade climática, captações d'água, barragens e mudanças climáticas, entre outros. A interferência da vegetação sobre o ciclo hidrológico ocorre, basicamente, pela transpiração, interceptação, capacidade de infiltração de água no solo e profundidade do sistema radicular (Bruijnzeel, 1989; McCulloch \& Robinson, 1993; Sahin \& Hall, 1996; Zhang et al., 2001) e, desta forma, modificações no uso do solo praticadas na bacia hidrográfica tendem a promover modificações no escoamento na bacia.

A modificação da paisagem vem sendo realizada, na maioria das vezes, irresponsavelmente, resultando na degradação dos mananciais, seja pela aceleração dos processos erosivos, alteração das disponibilidades hídricas, ou mesmo pela contaminação por defensivos agrícolas e lançamento de efluentes urbanos e industriais.

Neste sentido, estudos sobre a hidrologia de bacias hidrográficas e sua associação com a variabilidade climática e o uso do solo, consistem em uma demanda atual e de expressiva importância para o estabelecimento de medidas visando ao desenvolvimento sustentável, subsidiando as ações dos órgãos responsáveis pela gestão de recursos hídricos (Bosh \& Hewlet, 1982; Calder, 1993; Cheng et al., 2002; Engel et al., 2005; Farley et al., 2005).

A Bacia Hidrográfica do Ribeirão João Leite apresenta área de $766,8 \mathrm{~km}^{2}$ e está localizada ao norte da capital goiana. Os recursos hídricos superficiais ali produzidos são os principais responsáveis pelo abastecimento urbano da cidade de Goiânia, GO, além de suprirem demandas de irrigação, piscicultura e de outras atividades ao longo da bacia. Nos últimos anos, a demanda por água na bacia hidrográfica do ribeirão João Leite tem superado sua disponibilidade hídrica o que, conciliado à baixa qualidade da água presente em muitos períodos do ano, tem gerado conflitos entre usuários.

Neste contexto, o objetivo no estudo foi realizar a classificação do uso do solo entre os anos de 1979 e 2005 e a análise qualitativa e quantitativa das vazões máxima, média, mínima e de referência, em função de alterações no regime pluvial e uso do solo.

\section{MATERIAL E MÉTODOS}

\section{Descrição da área de estudo}

O presente estudo contempla a bacia hidrográfica do ribeirão João Leite com seção de controle na estação fluvio- métrica Captação João Leite, mantida pela Companhia de Recursos Minerais de Goiás (CPRM), que drena uma área de $766,80 \mathrm{~km}^{2}$, entre as latitudes $16^{\circ} 13^{\prime}$ e $16^{\circ} 39^{\prime}$ 'Sul e longitudes $48^{\circ} 57^{\prime}$ e $49^{\circ} 11^{\prime}$ 'Oeste. O clima característico da bacia é quente e subúmido, prevalecendo inverno seco. A vegetação predominante é o cerrado ocorrendo também Cerradão, mata de galeria próxima aos cursos d'água, Floresta Tropical Subcaducifólia e Caducifólia (Bonnet, 2007).

O Ribeirão João Leite tem sua nascente nas proximidades do município de Ouro Verde de Goiás e faz parte do Complexo Hidrográfico da Bacia do Rio Paraná. Após percorrer aproximadamente 85 km o Ribeirão João Leite deságua no Rio Meia Ponte que por sua vez, se estende por $415 \mathrm{~km}$ até sua foz, no Rio Paranaíba. Na divisa entre os estados de Minas Gerais, Mato Grosso do Sul e São Paulo, o Rio Paranaíba recebe afluência do Rio Grande, formando o Rio Paraná, que percorre cerca de $2.500 \mathrm{~km}$, unindo-se ao Rio Uruguai, na Argentina, originando o Rio da Prata.

Na Figura 1 se apresentam as sedes dos principais municípios inseridos na bacia. Conforme se pode visualizar, ao sul está localizada a cidade de Goiânia, capital do estado, que tem no Ribeirão João Leite seu principal manancial de abastecimento, suprindocerca de $52 \%$ de sua população, embora, outros municípios de grande expressão no cenário goiano estejam ligados diretamente à bacia em estudo, como é o caso, a leste, de Anápolis, evidenciando a necessidade de uma retratação adequada da interação entre uso do solo e hidrologia.

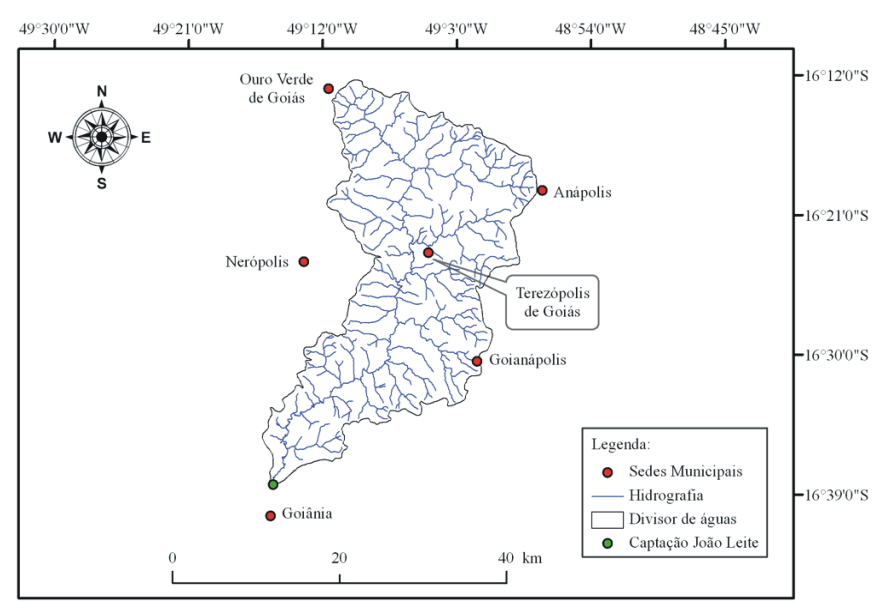

Figura 1. Bacia Hidrográfica do Ribeirão João Leite, hidrografia e sedes municipais

\section{Séries históricas}

A partir da série histórica de vazões médias diárias da estação fluviométrica Captação João Leite foram trabalhadas, de 1979 a 2005, séries de vazões média anual e mensal, máxima anual, mínima anual e mínima média de sete dias consecuti$\operatorname{vos}\left(\mathrm{Q}_{7}\right)$ e também geradas séries históricas anuais das vazões com permanência de 90 e $95 \%$ no tempo, $\mathrm{Q}_{90}$ e $\mathrm{Q}_{95}$, respectivamente, obtidas das curvas de permanência anuais.

A geração das curvas de permanência seguiu metodologia descrita por Jacobs \& Voguel (1998), a qual consiste em ordenar todos os dados de vazão em ordem decrescente e associar, a cada valor, uma frequência de excedência, utilizando 
uma posição de plotagem empírica $(\mathrm{m} / \mathrm{n}+1)$, sendo $\mathrm{m}$ a ordem do valor ordenado e n o número de valores da série.

Calculou-se, para a análise do regime pluvial, a precipitação média diária na bacia, de 1979 a 2005, utilizando-se informações de precipitação diária de 14 estações pluviométricas localizadas no interior e arredores da Bacia do João Leite, através da metodologia dos polígonos de Thiessen. De acordo com esse autor, a aplicação da referida técnica decorre do fato de que, conhecida a área de influência de cada estação pluviométrica, há possibilidade de se aplicar os fa- tores de ponderação a longas séries históricas, diferentemente de outras metodologias, que exigem a análise dos dados de cada evento; assim se obtiveram séries históricas de precipitação média anual e mensal.

\section{Classificação do uso do solo}

Visando descrever a variação temporal da cobertura vegetal, empregaram-se imagens do satélite Landsat dos anos de 1979, 1989, 1997 e 2005, apresentadas na composição RGB, na Figura 2.

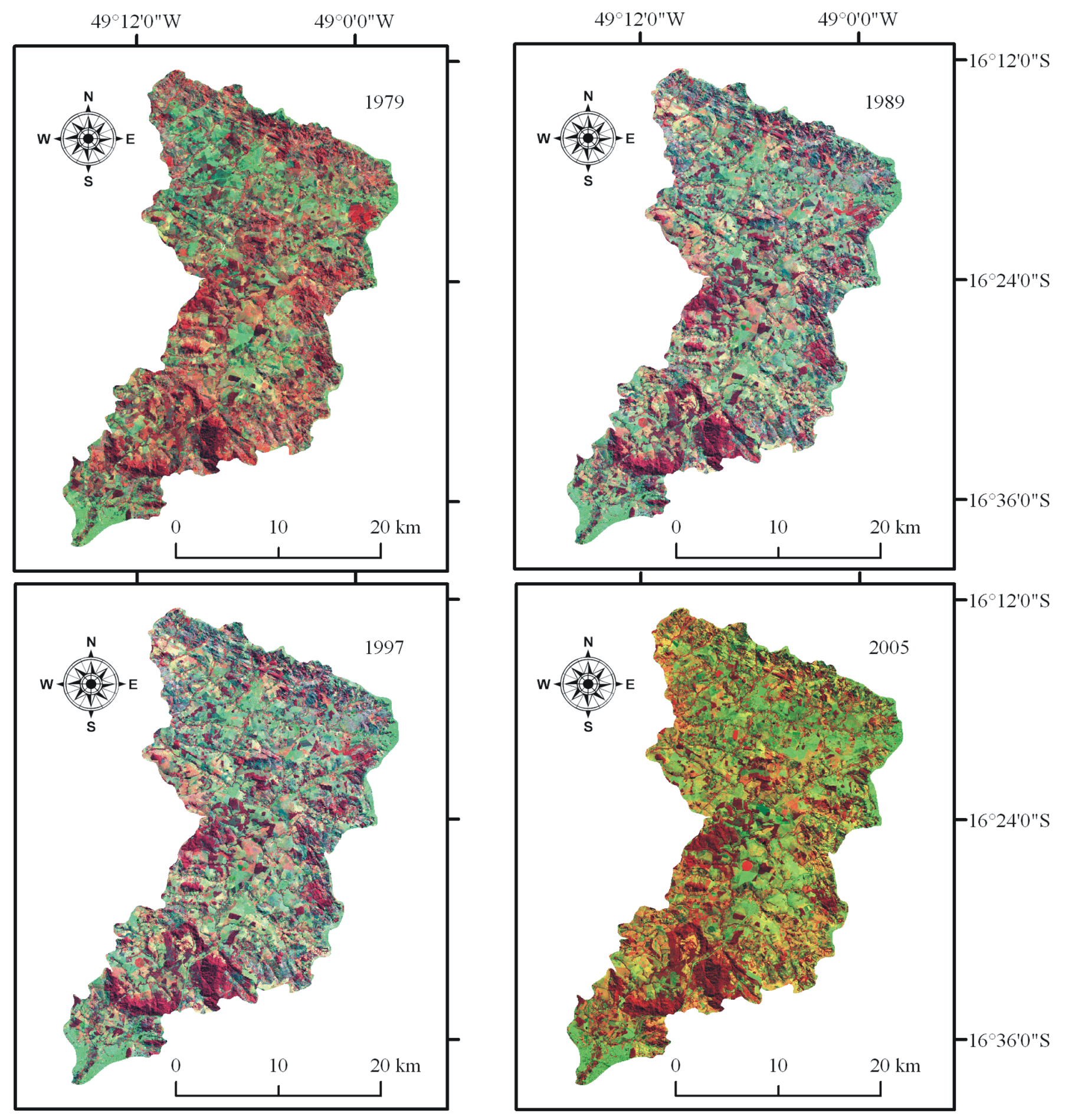

Figura 2. Composição RGB das imagens Landsat dos anos de 1979, 1989, 1997 e 2005 
A classificação do uso do solo na bacia do ribeirão João Leite foi realizada com o software SPRING (2005). O préprocessamento das imagens contemplou o realce do histograma, filtragem, verificação da correção geométrica e segmentação.

Adotou-se o método de classificação supervisionada pixel a pixel da máxima verossimilhança e se estabeleceram as classes de uso do solo pastagem, vegetação nativa, urbanização, água, solo exposto e agricultura, tendo-se estabelecido um número mínimo de 50 amostras por classe.

\section{Análise da tendência do comportamento hidrológico}

A metodologia empregada na análise da tendência das variáveis hidrológicas precipitação e vazão foi a descrita por Pruski et al. (2005), Pereira et al. (2005), Sharma \& Shakya (2006) e Latuf (2007). O método consiste em estimar equações de regressão linear simples entre a variável hidrológica (considerada variável dependente) e o tempo (variável independente), o que permite a identificação da propensão de mudanças das variáveis estudadas ao longo do período analisado (Pereira et al., 2005).

Após o ajuste da linha de tendência foi obtida a significância dos parâmetros da equação, conforme descrito por Pruski et al. (2005). De acordo com o autor, esta etapa visa avaliar a probabilidade da variação da variável dependente ser decorrente da alteração atribuída à variável independente.

\section{Associação entre o uso do solo e o regime fluvial}

De acordo com Bruinjnzeel (1988), Andreassian (2004) e Brown et al. (2005), os impactos das alterações na vegetação da bacia hidrográfica sobre o escoamento podem, de maneira geral, ser avaliados em termos de vazões mínimas, médias e máximas.

Realizou-se a análise quantitativa da associação entre o uso do solo e as vazões, por meio do ajuste de equações por regressão linear simples, conforme descrito por Latuf (2007). Neste sentido se obtiveram equações visando descrever o comportamento da vazão média anual, mínima anual, máxima anual, $\mathrm{Q}_{90}, \mathrm{Q}_{95}$ e $\mathrm{Q}_{7}$ usando-se como variáveis explicativas, as classes de uso do solo (vegetação nativa, pastagem, agricultura, urbanização, solo exposto e água), além das precipitações total anual $(\mathrm{P})$, total anual do ano anterior (Pant), média dos dois últimos anos (P2), do mês mais seco (Pms) e do mês mais chuvoso (Pmc).

Para a escolha das variáveis explicativas se empregou o teste t de Student, utilizando-se na regressão, variáveis que se mostrassem significativas a nível de $10 \%$ de probabilidade pelo teste. A verificação da qualidade do ajuste foi realizada pelo coeficiente de determinação $\left(\mathrm{R}^{2}\right)$. Nesta etapa do estudo se utilizou o programa de livre acesso R (R Development Core Team, 2006).

\section{RESULTADOS E DISCUSSÃO}

Classificação da cobertura vegetal e variabilidade temporal Apresentam-se, na Figura 3, os mapas de uso do solo obtidos para a Bacia Hidrográfica do Ribeirão João Leite, se- guido dos percentuais ocupados por cada classe na Tabela 1.

Observa-se que, no ano de 1979, quando se iniciou a avaliação do uso do solo, a bacia já se encontrava fortemente antropizada, o que pode ser afirmado com base na larga abrangência apresentada pelas classes de uso do solo agricultura e pastagem, que totalizaram $59,1 \%$ da bacia.

Tabela 1. Área ocupada por classe de uso do solo, em termos percentuais da área total, nos anos de 1979, 1989, 1997 e 2005

\begin{tabular}{lrrrr}
\hline Classe de uso do solo & $\mathbf{1 9 7 9}$ & $\mathbf{1 9 8 9}$ & $\mathbf{1 9 9 7}$ & $\mathbf{2 0 0 5}$ \\
Vegetação Nativa & 34,3 & 22,6 & 19,0 & 16,5 \\
Água & 0,4 & 0,8 & 1,3 & 0,8 \\
Urbanização & 4,2 & 6,1 & 7,0 & 10,8 \\
Agricultura & 18,4 & 19,3 & 26,4 & 33,6 \\
Solo exposto & 2,1 & 7,4 & 4,0 & 2,4 \\
Pastagem & 40,7 & 43,9 & 42,2 & 35,9 \\
\hline
\end{tabular}

As áreas de pastagens ocupadas tipicamente por forrageiras do tipo Capim Colonião, Napier e Jaraguá, representam a classe de uso do solo predominante na bacia do ribeirão João Leite, mantendo-se em torno de $40 \%$ entre os anos de 1979 e 1997, e sofrendo uma retração em 2005, para 35,9\%. De acordo com Afonso (2004), a principal atividade econômica exercida na bacia do João Leite é a agropecuária, justificando a elevada participação dessa classe na paisagem. Visualizando-se os mapas de uso do solo, constata-se a ocorrência de pastagens por praticamente toda a bacia hidrográfica, exceto em pequenas extensões ocupadas por vegetação nativa e urbanização, reforçando o diagnóstico inicial de tendência agropecuária.

A área ocupada por agricultura, seguindo o comportamento da classe pastagem, foi encontrada em praticamente toda a extensão da bacia. Em termos de área, entre os anos de 1979 e 1989 esta classe ocupou aproximadamente 19\% da bacia, a partir de quando sofreu expansão, alcançando $26,4 \%$ em 1997 e 33,6\% em 2005. Basicamente se cultivam, na bacia, hortaliças, frutíferas e culturas anuais, e se atribui a expansão desta classe de uso do solo ao desenvolvimento do eixo Goiânia - Anápolis - Brasília, que em 2005 se aproximava dos 6 milhões de habitantes.

As principais áreas urbanas presentes, como se observa nos mapas de ocupação do solo, correspondem a uma fração da cidade de Goiânia, localizada ao extremo sul da bacia, e outra de Anápolis, localizada a nordeste. Em 1979, a classe de uso do solo urbanização representou uma pequena parcela da área total, com um equivalente a 4,2\%; no entanto, verificou-se uma expansão contínua dessa classe passando a 6,1\% em 1989, 7,0\% em 1997 e 10,8\% em 2005.

Atualmente se encontra em construção, na Bacia do Ribeirão João Leite um reservatório de acumulação de água, que irá inundar aproximadamente $10,4 \mathrm{~km}^{2}$, com o objetivo de suprir a demanda hídrica da população de Goiânia, mas a classe água apresentou pequena variação durante o período analisado, atribuído à pequena variação da área ocupada por espelhos d'água ao longo dos anos.

De acordo com Bonnet (2005) a vegetação nativa da bacia do ribeirão João Leite abrange Cerrado, Cerradão, vege- 

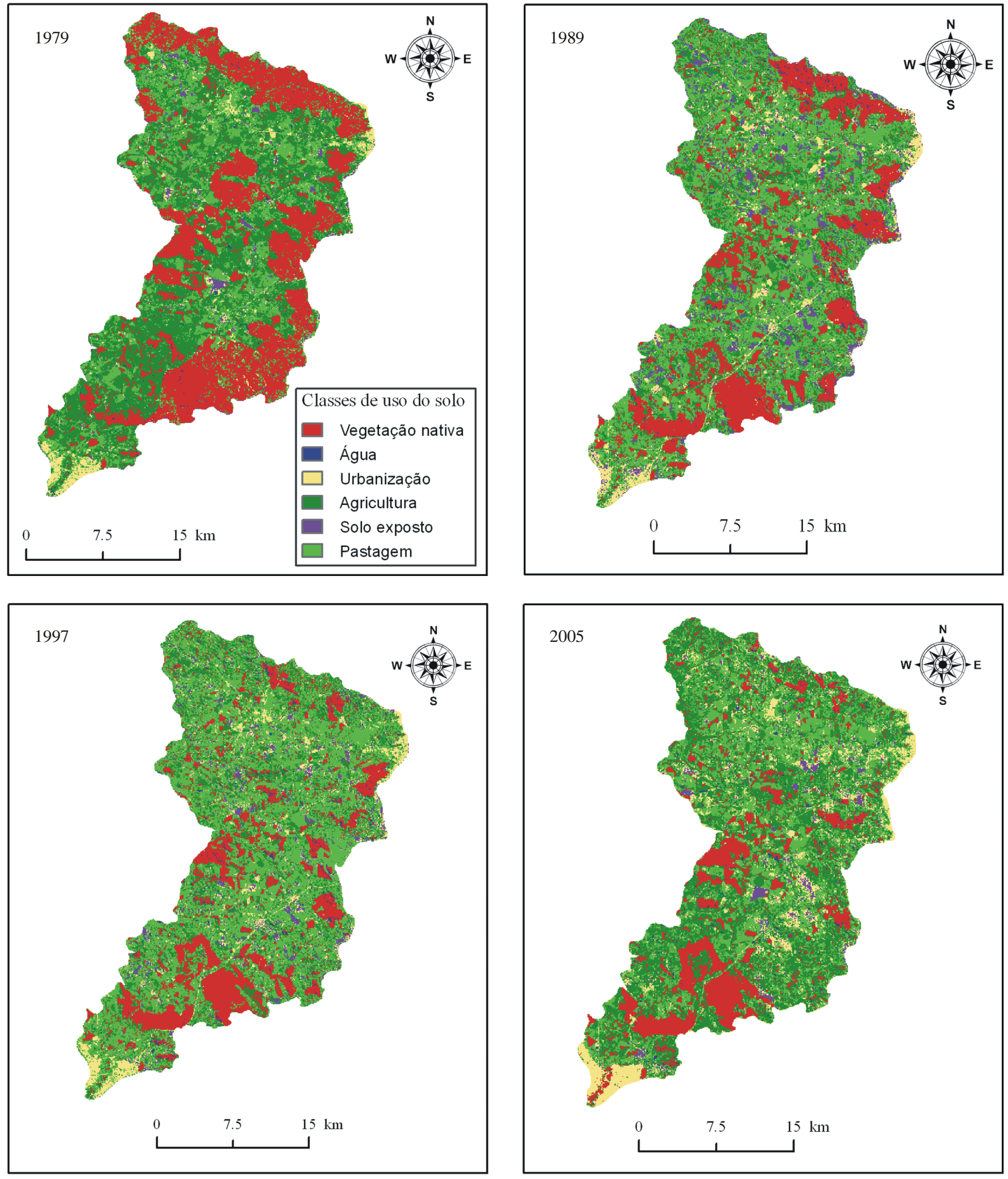

Figura 3. Classificação do uso do solo da bacia do ribeirão João Leite em 1979, 1989, 1997 e 2005

tação ciliar composta de mata de galeria, Floresta Tropical Subcaducifólia e Caducifólia. Visualizando-se o mapa de uso do solo obtido para o ano de 1979, observam-se algumas áreas de mata conservadas na cabeceira da bacia, porção central e toda a vertente leste, totalizando $34,3 \%$ da área.
Acompanhando o panorama brasileiro, a bacia do ribeirão João Leite passou por um processo intenso de desmatamento no período compreendido entre 1979 e 2005, no qual a área ocupada por vegetação nativa passou gradativamente de 262,9 para $173,1,145,9$ e $126,6 \mathrm{~km}^{2}$ nos anos de 1979,1989 , 
1997 e 2005, respectivamente; contudo, a análise do mapa de uso do solo do ano de 2005 mostrou que, ao longo da bacia, restaram pequenos fragmentos de vegetação nativa e, conforme também constatado por Bonnet (2007), não são respeitados os $20 \%$ de reservas legais e $10 \%$ de áreas de preservação permanente previstos em lei, com exceção da área do Parque Ecológico de Preservação Ambiental e Florestal Altamiro de Moura Pacheco, fundado em 1992.

A sexta classe de uso do solo avaliada nesse estudo foi a de solo exposto, constituído principalmente por voçorocas, pastagens degradadas e terra arada. Pode-se perceber que esta classe apresentou pequena participação e variação na ocupação do solo da bacia do ribeirão João Leite, com valor máximo de 7,4\% em 1989 e mínimo de 2,1\% em 1979.

\section{Interação do uso do solo e regime pluvial com o regime hidrológico}

\section{Vazões médias}

No período de 1979 a 2005 as vazões médias na bacia hidrográfica do ribeirão João Leite apresentaram valor de longo termo próximo a $10,93 \mathrm{~m}^{3} \mathrm{~s}^{-1}$. Durante este período, a precipitação média anual apresentou tendência de redução, da ordem de $6,39 \mathrm{~mm}^{2} \mathrm{ano}^{-1}$, com significância de 53,39\%. Refletindo a tendência de declínio apresentada pelo regime pluvial, o deflúvio médio anual indicou comportamento semelhante, com magnitude próxima a $6,78 \mathrm{~mm}^{\mathrm{ano}} \mathrm{o}^{-1}$, e significância de 96,65\%; desta maneira, fica evidenciado que a variabilidade climática explica, ao menos parcialmente, as alterações da variável de saída do ciclo hidrológico na bacia do ribeirão João Leite; contudo e conforme ilustra a Figura 4 , houve tendência de redução mais acentuada do escoamento, em comparação com a precipitação, de $0,38 \mathrm{~mm}^{\mathrm{ano}}{ }^{-1}$. Embora esta redução seja aparentemente pouco expressiva em termos de lâmina, quando ela é convertida em volume assume um valor de $291.384 \mathrm{~m}^{3} \mathrm{ano}^{-1}$, uma vez que a área de drenagem é de 766,8 km².

Conforme referido, a ocupação do solo na bacia hidrográfica do ribeirão João Leite passou por intensas modificações

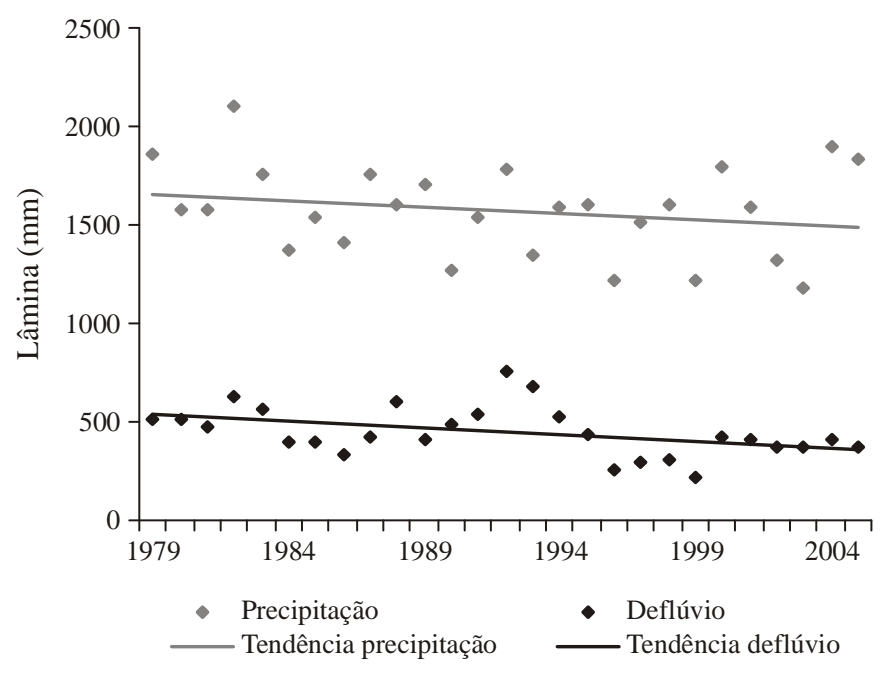

Figura 4. Precipitação média anual e deflúvio anual na bacia do ribeirão João Leite, GO, em mm, de 1979 a 2005 e linhas de tendência entre os anos de 1979 e 2005. A área inicialmente ocupada por vegetação nativa, que era da ordem de $263 \mathrm{~km}^{2}$, passou para $127 \mathrm{~km}^{2}$ em 2005. De acordo com Collischonn et al. (2001), após o desmatamento de florestas naturais ocorre aumento da vazão média na bacia hidrográfica. Ainda segundo estes autores, quando são implantadas culturas agrícolas em lugar da vegetação natural, os impactos podem ser diferenciados; no caso de culturas perenes, como o café, a alteração no escoamento é amenizada em comparação com culturas anuais, especialmente quando não é utilizado o plantio direto.

A expansão da área de agricultura, que se deu basicamente sobre áreas anteriormente ocupadas por vegetação nativa e pastagens, em termos absolutos respondeu pela maior alteração na cobertura vegetal, que foi de $117 \mathrm{~km}^{2}$; as referidas áreas foram ocupadas, ao longo da bacia, por culturas anuais e perenes utilizando-se basicamente, a técnica de preparo convencional do solo, na qual se tem, de maneira geral, redução da infiltrabilidade do solo em função da perda de matéria orgânica e também da compactação, devido ao tráfego intenso de máquinas agrícolas utilizadas no preparo do solo, o que indica tendência de aumento das vazões médias.

As áreas urbanas inseridas na bacia hidrográfica do ribeirão João Leite aumentaram em $157 \%$. Embora proporcionalmente pequena na bacia, a ocupação da classe urbanização teve um aumento de $51 \mathrm{~km}^{2}$. Do ponto de vista hidrológico, devido à impermeabilização da superfície do solo ocorre, em áreas urbanas, uma redução drástica da infiltração propiciando o aumento do escoamento superficial implicando, assim, em aumento de vazões máximas e médias e, por outro lado, reduzindo as vazões mínimas (Bruijnzeel, 1989) ficando evidente, portanto, que as alterações na cobertura vegetal da bacia do ribeirão João Leite no período de 1979 a 2005, tendem a proporcionar aumento do escoamento em detrimento da redução da capacidade de infiltração e interceptação em algumas áreas e, em outras, das diferentes características fisiológicas da nova vegetação implantada.

É de conhecimento geral que os processos de formação do escoamento são essencialmente não-lineares de maneira que a tendência de redução nos totais precipitados, embora acarrete redução no escoamento, as proporções envolvidas são de difícil detecção porém, conforme visto inicialmente, a tendência de redução do escoamento foi superior à do regime pluvial e as alterações da cobertura vegetal na bacia não explicam esta tendência; pode-se atribuir esta ocorrência ao expressivo aumento do volume de água captado ao longo do ribeirão João Leite, exercendo a retirada de um volume expressivo de água. Referido aumento decorre do crescimento acelerado, urbano e industrial, verificado nos entornos dos municípios de Goiânia e Anápolis nas últimas décadas, além do amplo desenvolvimento da agricultura irrigada por aspersão convencional e pivô central.

De acordo com a UFG (2003) a demanda hídrica na bacia do João Leite se deve principalmente ao abastecimento urbano chegando a $80,43 \%$ do total captado, sendo o restante destinado à irrigação $14,89 \%$, piscicultura $2,88 \%$ e outras atividades $1,81 \%$. Ainda de acordo com este autor e embora 
não existam registros históricos, a demanda hídrica atual é de $2,74 \mathrm{~m}^{3} \mathrm{~s}^{-1}$, o que resulta no impressionante volume captado, de $8,64.10^{7} \mathrm{~m}^{3}$ ano $^{-1}$.

Com o intuito de modelar as modificações na vazão média frente às alterações no regime pluvial e de ocupação do solo, empregou-se a regressão linear simples. Apresentaramse significativas a nível de probabilidade de $10 \%$ pelo teste $\mathrm{t}$ de Student, as variáveis vegetação nativa e $\mathrm{P}_{2}$. O modelo ajustado por regressão linear está apresentado na Eq. 1:

$$
\mathrm{Q}_{\mathrm{m}}=-7,6935+0,0838 \cdot \mathrm{VegNat}+0,0098 \cdot \mathrm{P}_{2} \quad\left(\mathrm{R}^{2}=0,98\right)
$$

em que $\mathrm{Q}_{\mathrm{m}}$ se refere à vazão média anual, em $\mathrm{m}_{3} \mathrm{~s}^{-1}$, VegNat à parcela da bacia ocupada por vegetação nativa, em \%, e $\mathrm{P}_{2}$ à precipitação média anual dos dois últimos anos, em mm.

\section{Vazões máximas}

Acompanhando o comportamento das vazões médias, as vazões máximas diárias anuais na bacia do ribeirão João Leite apresentaram tendência de decaimento no período de 1979 a 2005, que foi de $0,11 \mathrm{~m}^{3} \mathrm{~s}^{-1}$ ao ano, com significância de $42,37 \%$. Em termos de deflúvio diário a tendência de redução equivale a $0,01 \mathrm{~mm} \mathrm{~d}^{-1}$, magnitude pouco expressiva, tendo-se em vista a magnitude dos eventos críticos na bacia, que ultrapassam os $6 \mathrm{~mm} \mathrm{~d}^{-1}$.

Conforme visto, a principal alteração na cobertura vegetal na bacia do ribeirão João Leite consistiu no desmatamento da vegetação nativa em virtude, principalmente, da implantação da agricultura. De acordo com Collischonn et al. (2001), constam na literatura diversos estudos comparativos em pequenas bacias abrangendo a comparação de vazões máximas em bacias florestadas e desmatadas, os quais indicam que, com o desmatamento, ocorre aumento nas vazões máximas; no entanto, de acordo com Tucci \& Clarke (1997), o aumento ocorre sobre as vazões de pequeno e médio período de retorno, não influenciando significativamente as grandes cheias.

Conciliado a isto e de acordo com Bruijnzell (1996), a compreensão da influência das alterações da cobertura vegetal sobre o regime de vazões máximas é dificultada em função do armazenamento de água ao longo da calha de inundação.

Os resultados abordados pelos autores supracitados dão suporte às interpretações das alterações nas vazões máximas na Bacia Hidrográfica do Ribeirão João Leite, em que o vulto das grandes cheias sofreu pequenas alterações em decorrência das alterações do uso do solo; porém, a análise de variância entre as classes de uso do solo e precipitações com a vazão máxima anual, mostrou resultados significativos a nível de significância de $10 \%$ pelo teste t Student para as variáveis vegetação nativa e precipitação total anual. O resultado da regressão linear está apresentado na Eq. 2:

$$
\mathrm{Q}_{\max }=-53,5118+0,0483 \cdot \mathrm{P}_{\text {anual }}+0,3546 \cdot \mathrm{VegNat} \quad\left(\mathrm{R}^{2}=0,97\right)
$$

em que $\mathrm{Q}_{\max }$ é a vazão máxima anual estimada, em $\mathrm{m}^{3} \mathrm{~s}^{-1}$, $\mathrm{P}_{\text {anual }}$ é a precipitação total anual, em mm, e VegNat é a parcela da bacia hidrográfica ocupada por vegetação nativa, em \%.

\section{Vazões mínimas e de referência}

As vazões mínimas nos rios ocorrentes durante as estiagens refletem as condições de recarga do aquíffero; desta forma, o regime de chuvas, as condições de infiltrabilidade do solo e as características fisiológicas da cobertura vegetal, influem diretamente sobre elas.

A bacia hidrográfica do ribeirão João Leite passou por um intensivo processo de desmatamento no período de 1979 a 2005. Em florestas ocorre maior absorção da radiação solar em comparação com outras coberturas vegetais, culminando em maior energia disponível para evapotranspiração; outro fator a ser considerado é a interceptação, que é maior em áreas florestadas, incrementando a evaporação direta da água (Collischonn et al., 2001). Com relação à infiltrabilidade do solo após o desmatamento, deve-se observar as técnicas de manejo adotadas na nova cobertura vegetal, podendo ocorrer alterações significativas na lâmina infiltrada (Bruijnzeel, 1989).

De acordo com Tucci (2002) ocorrem, na literatura, experimentos que obtiveram aumento ou diminuição das vazões mínimas após o desmatamento da bacia hidrográfica, o que está intimamente relacionado com as alterações na superfície do solo após o desmatamento. De acordo com o autor, quando as condições de infiltração após o desmatamento são mantidas e, por consequência, a taxa de infiltração, ocorre aumento da recarga em detrimento da redução da evapotranspiração aumentando as vazões mínimas; por outro lado, se as condições de infiltração são prejudicadas, o escoamento superficial aumenta, reduzindo a recarga do aquífero e, por consequência, as vazões mínimas.

As vazões mínimas durante o período de 1979 a 2005 apresentaram tendência de redução de $0,07 \mathrm{~m}^{3} \mathrm{~s}^{-1}$ ao ano, ou $0,009 \mathrm{~mm} \mathrm{~d}^{-1}$, com significância de $94,58 \%$. Conforme visto, grande parte dessa tendência de redução pode ser explicada pela variabilidade do regime de chuvas, que apresentou tendência de decaimento de $6,39 \mathrm{~mm}^{2} \mathrm{ano}^{-1}$, com significância de 53,39\%.

O uso do solo pós-desmatamento na bacia do ribeirão João Leite, é marcado pela agricultura prevalecendo, em grande parte da bacia, o preparo convencional do solo; nesta técnica de cultivo prevalecem a perda de matéria orgânica do solo e a compactação, em virtude do tráfego de máquinas agrícolas, indicando que são esperadas reduções nas taxas de infiltração de água no solo favorecendo a formação do escoamento superficial e, assim, prejudicando as condições de recarga e das vazões mínimas.

Este quadro, em conjunto com o aumento da retirada de água do Ribeirão João Leite visando atender ao aumento da demanda industrial, agrícola e urbana de água, justifica a tendência acentuada de redução das vazões mínimas.

A modelagem da vazão mínima e das vazões de referência frente à classificação do uso do solo e precipitações está apresentada nas equações de 3 a 6 . Os modelos obtidos por regressão linear para a estimativa da vazão mínima anual e da vazão mínima média de sete dias consecutivos $\left(\mathrm{Q}_{7}\right)$ empregaram, como variáveis explicativas, a vegetação nativa e a precipitação total anual do ano anterior $\left(\mathrm{P}_{\text {ant }}\right)$, que se mostraram significativas a nível de $10 \%$ de probabilidade pelo 
teste $\mathrm{t}$ de Student; já para os modelos obtidos para as vazões com $90 \%$ de permanência $\left(Q_{90}\right)$ e $95 \%\left(Q_{95}\right)$, as variáveis explicativas que se mostraram significativas a nível de $10 \%$ de significância pelo teste $\mathrm{t}$ de Student, foram a vegetação nativa (VegNat) e a agricultura (Agr).

$$
\begin{aligned}
& \mathrm{Q}_{\min }=3,9152-0,2321 \cdot \operatorname{VegNat}-0,0051 \cdot \mathrm{P}_{\mathrm{ant}} \quad\left(\mathrm{R}^{2}=0,74\right) \\
& \mathrm{Q}_{95}=-1,6028+0,1609 \cdot \mathrm{VegNat}+0,0590 \cdot \mathrm{Agr} \quad\left(\mathrm{R}^{2}=0,84\right) \\
& \mathrm{Q}_{90}=-0,8577+0,1624 \cdot \mathrm{VegNat}+0,0490 \cdot \mathrm{Agr} \quad\left(\mathrm{R}^{2}=0,95\right) \\
& \mathrm{Q}_{7}=6,5842+0,2330 \cdot \mathrm{VegNat}-0,0066 \cdot \mathrm{P}_{\mathrm{ant}} \quad\left(\mathrm{R}^{2}=0,99\right)
\end{aligned}
$$

em que $\mathrm{Q}_{\min }$ é a vazão mínima anual, em $\mathrm{m}^{3} \mathrm{~s}^{-1}, \mathrm{Q}_{95}$ e $\mathrm{Q}_{90}$ são as vazões igualadas ou superadas em 95 e $90 \%$ do tempo, respectivamente, em $\mathrm{m}^{3} \mathrm{~s}^{-1} ; \mathrm{Q}_{7}$ é a vazão mínima média de sete dias consecutivos, em $\mathrm{m}^{3} \mathrm{~s}^{-1}$, VegNat é a parcela da bacia ocupada por vegetação nativa, em \%, Agr é a parcela da bacia ocupada por agricultura, em $\%$ e $\mathrm{P}_{\text {ant }}$ é a precipitação total anual do ano anterior, em $\mathrm{mm}$.

\section{CONCLUSÕES}

1. A análise temporal do uso do solo na bacia revelou que no ano de 1979, no qual se iniciou o estudo, a bacia já se encontrava bastante antropizada, com as classes de uso do solo agricultura e pastagem abrangendo cerca de $59 \%$ de sua área. Observou-se um processo constante de desmatamento da vegetação nativa, passando de $34,3 \%$ de vegetação nativa preservada no ano de 1979 para cerca de 16,5\% em 2005.

2. Constatou-se que a variabilidade climática explica, ao menos parcialmente, as alterações do escoamento na bacia do ribeirão João Leite, no período de 1979 a 2005; contudo, a associação entre os efeitos esperados das alterações no uso do solo sobre o escoamento foi prejudicada pelo expressivo aumento do volume de água captado.

3. Os modelos ajustados por regressão linear para modelar as modificações nas vazões média, máxima, mínima, $\mathrm{Q}_{7}$, $\mathrm{Q}_{95}$ e $\mathrm{Q}_{90}$, frente às alterações no regime pluvial e de ocupação do solo, mostraram um bom ajuste, admitido com base nos valores do coeficiente de determinação.

\section{LITERATURA CITADA}

Afonso, A. A. Avaliação do potencial de risco de contaminação por agrotóxico das águas superficiais da Microbacia do Ribeirão João Leite. Goiânia: IESA/UFG. 2004. 131p. Dissertação Mestrado

Andréassian, V. Waters and forests: From historical controversy to scientific debate. Journal of Hydrology, v.291, p.1-27, 2004.

Bonnet, B. R. P. Relações entre qualidade de água e uso do solo em bacias hidrográficas no cerrado brasileiro: Aspectos físicos e sociais e proposição de diretrizes. Goiânia: UFG, 2007. 125p. Tese Doutorado
Bosh, J. M.; Hewlett, J. D. A review of catchment experiments to determine the effect of vegetation changes on water yield and evapotranspiration. Journal of Hydrology, v.55, p.3-23, 1982.

Brown, A. E.; Zhang, L.; McMahon, T. A.; Western, A. W.; Vertessy, R. A. A review of paired catchment studies for determining changes in water yield resulting from alterations in vegetation. Journal of Hydrology, v.310, p.28-61, 2005.

Bruijnzeel, L. A. (De)forestation and dry season flow in the tropics: A closer look. Journal of Tropical Forest, v.1, n.3, p.229-243, 1989.

Calder, I. R. The balquhidder catchment water balance and process experiment results in context: what do they reveal Journal of Hydrology, v.145, p.467-477, 1993.

Cheng, J. D.; Lin, L. L.; Lu, H. S. Influence of forests on water flows from headwater watersheds in Taiwan. Forest Ecology and Management, v.165, p.11-28, 2002.

Collischonn, W.; Tucci, C. E. M.; Clarke, R. T. Further evidence of changes in the hydrological regime of the River Paraguay: Part of a wider phenomenon of climate change? Journal of Hydrology, v.245, p.218-238, 2001.

Engel, V.; Jobbagy, E. G.; Stieglitz, M.; Williams, M.; Jackson, R.B. The hydrological consequences of eucalyptus afforestation in the Argentine Pampas. Water Resources Research, v.41, p.1-14, 2005.

Farley, K. A.; Jobbagy, E. G.; Jackson, R. B. Effects of afforestation on water yield: A global synthesis with implications for policy. Global Change Biology, v.11, n.10, p.1565-1576, 2005.

Jacobs, J. M.; Voguel, R. M. Optimal allocation of water withdrawals in a river basin. Journal of Water Resources Planning and Management, v.124, n.6, p.142-158, 1998.

Latuf, M. O. Mudanças no uso do solo e comportamento hidrológico nas Bacias do Rio Preto e Ribeirão Entre Rios.Viçosa: UFV, 2007. 138p. Dissertação Mestrado

McCulloch, J. S. G.; Robinson, M. History of forest hydrology. Journal of Hydrology, v.150, p.189-216, 1993.

Pereira, S. B.; Pruski, F. F.; Novaes, L. F. ; Silva, D. D. da ; Ramos, M. M. Análise do comportamento hidrólogico do rio Verde Grande. Engenharia na Agricultura, v.13, n.1, p.55-60, 2005.

Pruski, F. F.; Pereira, S. B.; Novaes, L. F.; Silva, D. D.; Ramos, M. M. Comportamento hidrológico na Foz do Rio São Francisco durante período de 1950 a 1999. Engenharia na Agricultura, v.13, n.2, p.118-123, 2005.

R Development Core Team. R: A language and environment for statistical computing. Viena: R Foundation for Statistical Computing, 2006, 97p.

Sahin, M. J.; Hall, M. J. The effects of afforestation and deforestation on water yields. Journal of Hydrology, n.1178, p.239-309, 1996.

Sharma, R. H.; Shakya, N. M. Hydrological changes and its impacto $\mathrm{n}$ water resources of Bagmati watershed, Nepal. Journal of Hydrology, v.11.051, p.315-322, 2006.

SPRING - Sistema de Processamento de Informações Georreferenciadas. v.4.2. São José dos Campos: INPE/DPI, 2005. 247p.

Tucci, C. E. M. Impactos da variabilidade climática e uso do solo sobre os recursos hídricos. Brasília: Agencia Nacional de Águas, 2002. 150p. 
Tucci, C. E. M.; Clarke, R. T. Impacto das mudanças de cobertura vegetal no escoamento: Revisão. Revista Brasileira de Recursos Hídricos, v.2, n.1, p.135-152, 1997

UFG - Universidade Federal de Goiás. Recomendações referentes de uma base de dados técnicos como subsídio para outorga de direito de uso dos recursos hídricos superficiais na Bacia Hidrográfica do Rio Meia Ponte - GO. Goiânia: UFG, 2003. 192p.

Zhang, L.; Dawes, W. R.; Walker, G. R. Response of mean annual evapotranspiration to vegetation changes at catchment scale. Water Resources Research, v.37, n.3, p.701-708, 2001. 